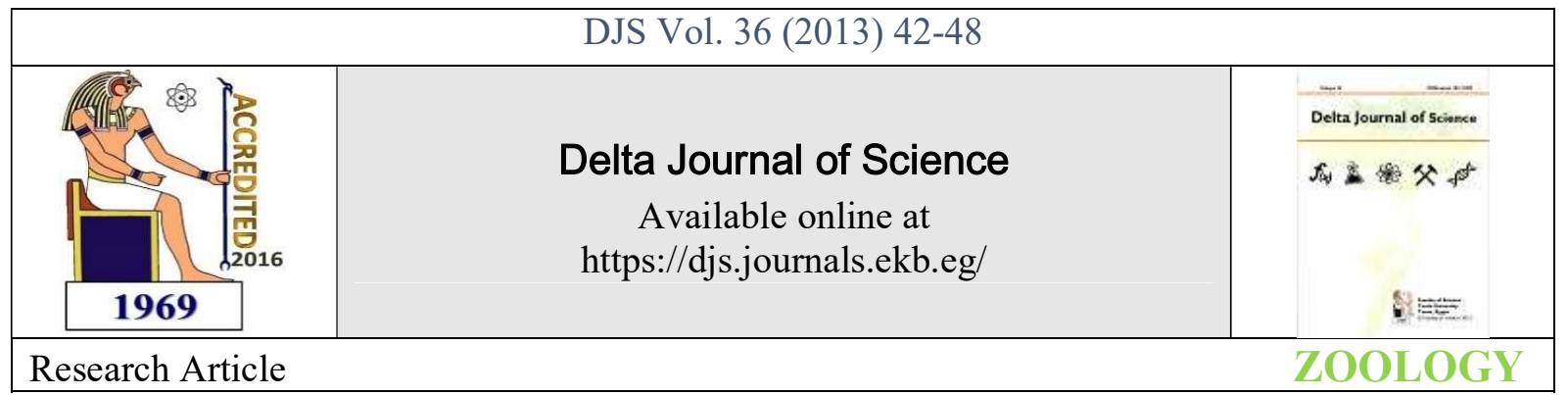

\title{
In vivo effects of diminazene aceturate (berenil) ontrypanosoma evansiinfectionin mice: ascanningelectron microscopy study.
}

\author{
Nabila M. Mira, Said E. Amer and Magdy E. Mahfouz \\ Department of Zoology, Faculty of Science, Kafrelsheikh University
}

\begin{abstract}
Chemotherapy is the main approach of trypanosomal control. This study aims to examine the efficiency of the commonly used antitrypanosomal drug Diminazene aceturate (DIMA) or Berenil against Trypanosoma evansi, in vivo. The criteria used for assessment of the antitrypanosomal effect included the examination of the host blood as well as monitoring the morphological changes inT. evansi as seen by SEM. Sixty Swiss albino mice, groups of fifteen, were employed. These animals were divided into four groups; non-infected and non-treated control, infected with locally isolated $T$. evansi strains receiving no treatment, infected-treated with DIMA $(20 \mathrm{mg} / \mathrm{kg})$ sacrificed after 4 hand $8 \mathrm{~h}$ post treatment, respectively.SEM demonstrated that infection with $T$. evansi produced several alterations in RBCs structure including the appearance of microspherocytes, schistocytosis, aggregation, doughnut-cell formation, keratocytosis and increment of the biconcave appearance of cell diskocytes. In addition, RBCs were constantly observed to adhere firmly to trypanosomes. After 4 and $8 \mathrm{~h}$ of DIMA treatment, the cells aggregated were dispersed and the biconcave disk shapes of RBCs create large and stable contact area between adjacent cells. These results also indicated that, in comparison to the untreated group that display normal $T$. evansimorphology and surface topology, parasite exposed to DIMA for $4 \mathrm{~h}$ revealed a number of morphological alterations in the body shape including rounding of the parasite's body and in several instances, shortening of the flagellum. Following $8 \mathrm{~h}$ of treatment, drastic morphological changes were observed with torsion and shortening of the body, sometimes with the aspect of a tadpole-shape and a pronounced reduction in the size of the parasite, while the region of the free flagellum was preserved.This study demonstrates the potential of DIMA in vivo in the treatment of trypanosomiasis.
\end{abstract}

Key words: Diminazene, Trypanosoma evansi, Miceinfection, Scanning electron microscopy

\section{INTRODUCTION}

Trypanosomes(T), single-celled blood parasites, are awiderange of blood parasites, whichcause trypanosomiasis in both humanand animals such as T. rhodesiense, T. vivaxs, $T$. brucei,T. gambiense, T. congolense and T. evansi (Alsaffaret al., 2007). The protozoan parasite $T$. evansicauses a trypanosomosis disease that is known as surra. It affects a large number of wild and domesticated animal species in Africa, Asia, and Central and South America. The principal host species varies geographically, but camels, horses, buffalos and cattle are particularly affected, although other animals, including wildlife, are also susceptible. In Egypt, the disease causes significant losses in camels, beside considerable economic damage due to a decrease in milk and meat, premature births and abortions (Abdel-Rady 2008). As an arthropod-borne disease; several species of haematophagous flies, including Tabanids and Stomoxes, are implicated in transferring infection from host to host, acting as mechanical vectors (Womacket al., 2001; WHO, 2006; Adeymiet al., 2009).

Because of their presence in the blood, Trypanosomes produce numerous changes in the cellular and biochemical constituents of blood (Igbokweand Mohamed, 1992; Taiwoet al., 2003). For example, Trypanosoma brucei infection leads to increased red blood cell destruction that results in anemia as well as tissue damage (Ekanem and Yusuf, 2008; Akanjiet al., 2009). Whereas, rabbits experimentally infected with $T$. evansi produced a number of morphological changes in RBCs including the presence of anisocytosis, pokilocytosis, target cells, macrocytes, Howell-Jolly bodies, Burr cells (as an indicator of renalfailure) and stomatocytes (Alsaffaret al., 2007).

Control of trypanosomiasis depends mainly on the use of curative and prophylactic drugs as insect control within the 
necessary scale is prohibitively expensive and vaccine development seems particularly impossible because of the process of antigenic variation of African trypanosomes (Tekaet al. 2009). One of the few drugs available for chemotherapy of animal infections of the haemoflagellate parasitic protozoa T.bruceibrucei, T. congolense and T. vivax is DIMA (Berenil: N-1,3 diamidino-phenyl triazenediaceturate, tetrahydrate, usually referred to simply as diminazene) whose trypanocidal activity was first reported by Bauer (1955 a,b) and Fussganger(1955). Its usefulness and tolerance has been extensively investigated (Aneneet al., 1997 and Tuntasuvanet al., 2003). Many investigators have reported therapeutic trials of $T$. evansi with the use of different chemotherapeutic drugs (Homeidaet al., 1980; Bacchiet al. 1998 and Tuntasuvanet al., 2003). Single doses of 10 and 20 $\mathrm{mg} / \mathrm{kg}$ of berenil given intraperitoneally to infected mice, produced a complete elimination of the protozoon and caused a slow tissue recovery mirrored in the persistence of lesions in different organs (Elaminet al., 1982).The pharmacokinetic of diminazene alone has been investigated in sheep and goat (Mammanand Peregrine, 1994), cattle (Klat and Hajdu,1976; Aliuet al., 1993), pregnant and lactating caws (Madachiet al., 1995) and caw calves (Kellnenet al., 1985; Kauret al., 2000). Furthermore, the efficacy of DIMA in the control of the $T$. evansi infection in a number of hosts such as cats (Da Silva et al., 2009) and rats (Toninet al., 2011) was examined. However, the mechanism of action and in vivo behavior of the drug is still poorly understood (Miller, 2005) and in turn the ultrastructure changes in $T$. evansi following in vivo treatment have not been demonstrated.The present study was planned with a view to assess the in vivo trypanocidal efficacy of DIMA in mice taking into account the morphological changes in the parasite as well as the blood using SEM.

\section{Materials and methods}

\section{Animals}

T. evansi has a broad spectrum of infectivity for small rodents and mice are often used to reveal subclinical (non-patent) infections in domesticated animals (Monzonet al., 1990).Sixty outbred Swiss albino mice weighting between 25-30 gm and aging 3-4 months were utilized. They were fed on control diet containing $200 \mathrm{gm}$ protein/kgad libitum. The animalswere divided into 4 groups of 15 animals, each.

\section{Parasite}

T. evansi strain was derived from naturally infected camels brought to El-Basatein abattoir, Cairo-Egypt.Five milliliters of heparinized blood were collected from each camel. Mice were intraperitonealy (i.p.) inoculated with one milliliter heparinized blood of positively infected camels. To establish an in vivoculture system, the parasite was injected into uninfected mice i.p. and maintained in other mice by repeated passing. Animals were bled from the tail after every 48 hours to detect parasitaemia. Awet film and haematocrit buffy coat methods (Murrayet al., 1983) were used for the initial detection of parasitaemia. The degree of parasitaemia was estimated as previously described (Herbert and Lumsden, 1976).Infection was allowed to develop for 72 hours before treatment was initiated (Adenikeand Stephen, 2010).

\section{Drug:}

DIMA (Berenil®, Hoechst, Germany) was dissolved and reconstituted in distilled water according to manufacturer's instructions and administered i.p. to animals in a concentration of $20 \mathrm{mg} / \mathrm{kg}$ as recommended by a number of researchers (e.g. Elaminet al., 1982).

\section{Treatment of Animals}

The animals were divided as follows and received the appropriate dosage of the drug that corresponds to their body weight:

A- Group I- control; uninfected and non-treatedthat received neither infection nor treatment.

B- Group II- infected with an inoculumofT. evansi parasites and received no drug treatment.

C- Group III- infected with an inoculumofT. evansi parasites and treated with DIMA.The animals were sacrifiedafter 4hours post treatment.

D- Group IV- similar to group III but animals weresacrifiedafter 8 hours post treatment.

\section{Scanning electron microscopy (SEM)}

Parasites and blood were fixed with $2.5 \%$ glutaraldehyde, $2 \%$ formaldehyde in $0.1 \mathrm{M}$ cacodylate buffer (pH7.2)for 1 hour at room temperature under constant agitation.The fixed parasites were then decanted overnight on glass coverslips precoated with $0.01 \%$ poly-L-Lysin.The coverslips were washed three times with $0.1 \mathrm{M}$ cacodylate $\mathrm{pH}$ 7.2 (10 minutes each) and then incubated with $1 \%$ osmium tetroxide in the same buffer for 30 minutes at room temperature, washed with cacodylate buffer and treated for 30 minutes with $1 \%$ tannic acid solution. After this treatment coverslips were washed twice in distilled water (10 minutes each) and impregnated once more with $1 \%$ osmium tetroxide (30 minutes),gradually dehydrated in ethanol solutions (70, 90 and $100 \%$ ) and dried in a Balzers CPD 030 apparatus. The slides were mounted, gold coated in a Balzers SCD 050, and examined with JEOL5300 electron microscope in the Faculty of Science, Alexandria University.

\section{Results}

\section{Group 1}

The RBCs in this group showed normal architecture with a pronounced biconcave disk shape that creates a large and stable contact area between adjacent cells (Fig. A).

\section{Group II}

In this group of infected and untreated animals, parasitaemia was noticed to develop 6 days post infection.T. evansiexhibited typicalultrastructural features similar to those of other trypanosomes with elongated body,normal morphology and surface topologyas well as a typical free flagellum extension. The flagella arise and extend forming undulating membrane, which is thrown into folds, characteristically broad in certain parts and narrow in others (Figs. 1, 2, 3).

T. evansiinfection produced several alterations in RBCs structure. These included fusions of erythrocytes, aggregation, disintegration and cell swelling rupture that yielded erythrocyte ghosts (Figs. 5, 6). In addition, a number of morphological changes in RBCs structure were displayed such as the appearance of microspherocytes, schistocytosis, vacuolationdoughnut-cell formation, and keratocytosis.Also,the thickness and cell diameter of the biconcave diskocytes increased in comparison to control group I. Meanwhile, RBCs were constantly observed to adhere firmly to the parasite (Figs. 7, 8, 9, 10).

\section{Group III}

Following $4 \mathrm{~h}$ of DIMA treatment, SEM examination of T. evansi showed a number of morphological changes in the shape of trypanosomes. A pronounced reduction in the size of the parasite was evident while the region of the undulating 
membrane and free flagellum were preserved (Fig. 11, 12). The treatment led to rounding of the parasite's body and swelling, meanwhile the cytoplasm contained many granules (Figs. 11,12,13,14).Also DIM A treatment led to deformation and disintegration of some parasites (Fig.13).The surface view of the blood in this group showed that the aggregation of RBCs, noticed in group II, is reduced (Fig.15).

\section{Group IV}

In this group where animals were treated with DIMA and scarified after(8h), SEM revealed the development of further morphological changes. These included more rounding and shortening of the body, sometimes with aspects of tadpole shape(Figs. 16, 17, 18,19). The surface view of the RBCs seems to be much close to normal when compared to the control group (Fig.20).

\section{Discussion}

We have characterized some morphological changes that occur in response to DIMA (Berenil) treatment of T. evansi, in vivo. The results obtained from this study clearly demonstrated that DIMAwas a powerful antitrypanosomal compound with a specific in vivo activity. Extensive controversy results could be perceived concerning the efficacy of acertain drug in both in vivo and in vitro studies. Kaminskyand Zweygarth (1989) reported that care must be taken when evaluating anti-trypanosomal drugs for in vitro potency because drugs might be inactive in the in vitro system but still be efficacious in vivo.

In the present study, a rapid rise in T. evansi parasitaemia was noticed. Such event is considered as a feature of this strain of trypanosome. Trypanosomes have the capacity to divide very rapidly resulting in their large population in the blood stream of host animal within short time (Umar et al., 2007).

Although DIMA did not completely eliminate the parasites from the blood stream of infected mice during the course of the study, but reduced the level of parasitaemia and induced drastic morphological changes. In the presence of DIMA, T. evansi presented changes in the cell morphology, which is characterized by a shorter and broader form than the typical long slender form found in the untreated group. One of the most evident morphological changes was the rounding of the body with occasional presence of a tadpole formation, while the region of the free flagellum was preserved. These morphological alterations agree with the findings of other researchers (e.g. Souto-Pardon et al.,1984 and Salomaoet al., 2010) who reported that morphological alterations, such as pronounced reduction in the size of the parasite and surface shrinkage, induced by megazol and its analogues may indicate destabilization of cytoskeleton components or microtubuleassociated proteins. Cyrus et al. (1983) reported that $\alpha$-DLDifluoromethylornithine treatment progressively limits the parasites' ability to synthesize nucleic acids and blocks cytokinesis while inducing morphological changes resembling long slender-short stumpy transformation. Also, parthenolide induced morphological alterations in the body shape of trypomastigote forms, causing rounding and shortening of the parasite and loss of integrity of the plasma membrane (Pelizzaroet al.,2010).Meanwhile, the effect of Suramin on trypomastigote forms of T.cruzi has been previously reported to inhibit cell enzymes and to affect the synthesis and distribution of cytoskeleton proteins(Danielle et al., 2006).Trypanin is a cytoskeletal connection between the flagellar apparatus and the subpellicular cytoskeleton. Procyclic trypomastigotes lacking trypanin lost their ability to coordinate flagellar beats and were incapable of directional cell motility (Hutchings et al., 2002).

Chemotherapeutic drugs disrupt or block one or more of the vital processes effects on some enzyme system or block essential metabolic pathways. The exact way in which they work is often not known or only incompletely understood (Zhang et al.,1991). Chemotherapy by stopping the multiplication of trypanosomes helps the immune system to overcome the infection (Osman et al.,1992).The prophylactic action of DIMA, in the field, would be enhanced by the host immune response (Gilbert, 1983). DIMA induced respiration deficient petite mutations in Saccharomyces cerevisiae (Mahler and Perlman, 1973; Perlman and Mehler 1973; Villa and Julian, 1980). It is thought that DIMA binds to yeast mitochondrial DNA (Perlman and Mahler 1973; Mahler 1973). Again, whether these findings are relevant to mammals is unknown although they appear to be involved in the trypanocidal activity of the drug possibly in association with the inhibitory effects of diamine oxidase and Sadenosylmethionine decarboxylase (Balana-Fouceet al., 1986).In the present study, the SEM studies demonstrated that $\mathrm{T}$. evansi produced several alterations in RBC structure including aggregation, doughnut-cell formation and keratocytosis. The mature RBCswere constantly observed to adhere firmly to trypanosomes in thin blood films. Other blood cells were not remarkably involved.This observation coincides with other findings of experiments done previously in deer mice experimentally infected with $\mathrm{T}$. brucei where mature erythrocytes were observed to adhere to trypanosomes (Anosa\& Kaneko, 1983b; Jenkins\& Facer, 1985). After treatment with DIM for 4 and $8 \mathrm{~h}, \mathrm{RBCs}$ aggregation was reduced and the biconcave disk shape of RBCs creates a large and stable contact area between adjacent cells. It seemed that the infection with trypanosomes resulted in increased the susceptibility of red blood cell membrane to oxidative damage probably as a result of depletion of reduced glutathione on the surface of the red blood cell (Igbokweet al.,1994;1996;Taiwoet al., 2003 and Akanjiet al.,2009).

In conclusion, the results of the present study demonstrated the in vivo effect of DIMA on T. evansi as evidenced by SEM. The administered drugs improved blood components, as indicated by RBCs condition, conceivably by deforming and destroying the parasites.

\section{References}

Abdel-Rady A. (2008): Epidemiological studies (parasitological, serological and molecular techniques) of Trypanosoma evansi infection in camels (Camelusdromedarius) in Egypt. Veterinary World, Vol.1 (11): 325-328.

Adenike S. F. and Stephen A. O. (2010). Changes in hematological indices and protein concentrations in Trypanosoma. EXCLI 9:39-45

Akanji M. A., Adeyemi O. S., Oguntoye S. O., and Solyman F. (2009): Psidiumguayava extract reduces Trypanosomosis associated lipid peroxidation and raises glutathione concentration in infected animals. EXCLI J 8: 148- 54.

Aliu, Y. O. Mamman, M. and Peregrine, A. S., (1993): Comparative pharmacokinetics of Diminazene in female boran (Bosindicus) Cattle. Vet. Pharmacol, Therap., 16: 291- 300.

Alsaffar A. H., Hassoon A. F. Farag A. H. (2007). Blood picture and hepatic changes in rabbits experimentally infected with Trypanosoma evansi. Iraqi strain. Medical Journal of Babylon, Vol 4 No. 3\& 4, pp 358-364. 
Anene, B. M., Anika, S. M. and Chukwu, S. C., (1997): Effect of idifluoromethylornithine after intravenous administration and its combination with diminazeneaceturation against Trypanosoma brucei in experimentally infected dogs in Nigeria. RevdElevage el de. Med. Vet. des. Pay. Trop., 50: 221- 225

Anosa, V.O. and KANEKO, J. J. (1983): Pathogenesis of Trypanosoma brucei infection in deer mice (Peromyscusmaniculatus): Light and electron microscopic studies on erythrocyte pathologic changes and phagocytosis. Am J Vet Res, v. 44, n. 4, p. 645-651.

Bacchi, C. J., M. Vargas; D. Rattendi, B. Goldberg and W. zohou. (1998): Antitrypanosomal activity of a new triazine derivative, SIPI 1029, in vitro and in model infections. Antimicrobial Agents Chemotherapy. 42(10):2718-2721.

Balana- Fouce,R., GarzonPulido, T., Ordonez-Escudero, D. and Garrido-Pertierra, A. (1986) : Inhibition of diamine oxidase and S- adeosylmethionine decarboxylase by Diminazeneaceturate (berenil). Biochem.Pharacol., 35: 15971600.

Bauer, F. (1955a): Ergebbnisse der KlinischePrufung von Berenil. VeterinarMedizinischeNachrichten, 3: 152-158.

Bauer, F. (1955b): Trypanosomen und BabesienErkrankungen in Afrika und ihreBehandlungmitdemneuenPraparat (Berenil). Z Tropenmed. Parasitol. 6:129-140.

Da Silva A. S., Zanette R. A., Wolkmer P., Costa M. M., Garcia H. A., Lopes S. T., Santurio J. M., Teixeira M. M., Monteiro S. G. (2009): Diminazeneaceturate in the control of Trypanosoma evansi infection in cats. Vet Parasitol. Oct 28; $165(1-2): 47-50$

Danielle, F.R. Bisaggio; Loraine Campanati; Rodrigo C.V Pinto and Thais Souto-Padron. (2006): Effect of suramin on trypomastigote forms of Trypanosoma cruzi: changes on cell motility and on the ultrastructure of the flagellum- cell body attachment region. ActaTropica .98: 162-175.

Ekanem J. T. and Yusuf O. k. (2008): Some biochemical and haematological effects of black seed (Nagella sativa) oil on $\mathrm{T}$. brucei infected rats. Afr J Biomed Res. 11: 79- 85.

Elamin, E. A., Homeida, A. M., S. E. I. and Mahmoud, M. M. (1982): The efficacy of berenil (diminazeneaceturate) against Trypanosoma evansi infection in mice. $\mathrm{J}$ Vet Pharm and Therap. 5:259-265.

Fussganger, R. (1955). Berenil in der Veterinarmedizin.VeterinarMedizinischeNachrichten, 3, 146151.

Gilbert R. J. (1983): Studies in rabbits on the disposition and trypanocidal activity of the antitrypanosomal drug, diminazeneaceturate (Berenil). British Journal of Pharmacology.Vol 80, Issue 1, pages 133-139.

Herbert, W.J. and Lumsden, W. H. R. (1976): Trypanosoma brucei: a rapid matching method for estimating the host's parasitaemia .Exp.

Homeida, A. M., E. A. Elamin, S. E. I. Adam and M.M. Mahmoud (1980): The effect of samorin (isometamedium chloride) on Trypanosoma evansi infection in mice. British Journal of experimental Pathology, 61:380-389

Hutchings, N. R., Donelson, J. E., and Hill, K. L. (2002): Trypanin is a cytoskeletal linker protein and is required for cell motility in African Trypanosomes. J. Cell Biol.156: 867677.
Igbokwe I. O. and Mohammed A. (1992): Some plasma biochemical changes in experimental Trypanosoma brucei infection in Sokoto red goats. Rev Elev Med Pays Trop. 45 (340): 287- 290.

Igbokwe I. O., Esievo K. A., Saror D. I., and Obagaiye O. K. (1994): Increased susceptibility of erythrocytes to in vitro peroxidation in acute Trypanosoma brucei infection in mice. Vet. Parasitol. 55: 279-86.

Igbokwe I. O., Umar I. A., Omage J. J., Ibrahim N. D. G., Kadima K. B., Obagaiye O. K., Saror D. I. and Esievo K. A. N. (1996): Effect of acute Trypanosoma vivax infection on cattle erythrocyte glutathione and susceptibility to in vitro peroxidation. Vet Parasitol. 63: 215- 24.

Jenkins, G.C. and Facer, C.A. (1985): Hematology of African Trypanosomiasis, in: TIZARD, I. Immunology and Pathogenesis of Trypanosomiasis. Boca Raton, Florida: C.R.C. Press, p. 13-44.

Kaminsky, R. and Zweygarth E. (1989): Feeder layer-free in vitro assay for screening antitrypanosomal compounds against Trypanosoma brucei and T. evansi. Antimicrobial Agents Chemotherapy, 33(6):881-885.

Kaur, G., Chaudhary, R. K., Srivastava, A. K. (2000): Disposition Kinetics of Diminazene in crossbred calves following intravenous administration. Indian Vet.J., 77: 673674

Kellnen, H. M., Eckert, H. G and Volz, M. H., (1985): Studies in rabbits on disposition and activity of the anti-Trypanosome drug. Diminazeneaceturate (Bernil). Br. J. Pharm., 80: 133139.

Klat, P., and Hojdu, P., (1976): Pharmacokinetics investigation on Diminazene and Rolitetracyline in comparison to combination of both. Vet. Rec., 99: 372- 374.

Madachi, R. E., Murilla, G. A., Omukush, J. N. and Congolati, V. (1995): Disposition of diminazeneaceturate (Berenil) in trypanosome infected pregnant and lactating cows. Vet. Parasitol., 58 : 215-225.

Mahler, H. R. (1973): Structural requirements for mitochondrial mutagenesis. J. Supramolec structure 1: 449460

Mahler, H. R. and Perlman, P. S. (1973): Induction of respiration deficient mutants in Saccharomyces cervisiae by berenil. I. Berneil, anovel, non-intercolacting mutagen. Molec. Gen. Genet., 121.

Mamman M. and Peregrine A. S. (1994): Pharmacokinetics of diminazene of plasma and cerebrospinal fluid of goats. Research in Veterinary Science 57: 253-255

Miller D. B. (2005).The pharmacokinetics of Diminazeneaceturate after intramuscular and intravenous administration in the healthy dog.Thesis University of Pretoria.

Monzon C. M., Mancebo O. A., Roux J. P. 1990. Comparison between six parasitological methods for diagnosis of Trypanosoma evansi in the subtropical area of Argentina. Vet Parasitol 36: 141-146.

Murray, M.; Trail, J. C. M.; Turner, D. A.; Wissoc, Y. (1983): Livestock productivity and Trypanotolerance: Network Training Manual. ILCA, Addis Ababa, Ethiopia, pp 4-10

Osman, A. S., F. W. Jennings and P. H. Holmes (1992): The rapid development of drug-resistance by Trypanosoma evansi in immunosuppressed mice. Acta Trop., 50(3): 249-257 
Pelizzaro-Rocha K. J.; Tiuman T. S.; Izumi E; UedaNakamura T.; Dias Fiho B. P., and Nakamura C. V. (2010): Synergistic effects of parthenolide and benznidazole on Trypanosoma cruzi. 15; 18 (1): 36-9.

Perlman, P. S. and Mahler, H. R. (1973): Induction of respiration deficient mutants in Saccharomyces cerevisiae by

Arylhydrazone derivatives of megazol against Trypanosoma cruzi. AmerSoc Microb.54 (5): 2023- 2031.

Souto-Padron, T., De Souza, W., Heuser, J. E., (1984): Quickfreeze, deep- etch rotator replication of Trypanosoma cruzi and Herpetomonasmegaseliae. J. Cell Sci.69:167-178.

Taiwo V. O., Olaniyi M. O., Ogunsanmi A. O. (2003): Comparative plasma biochemical changes and susceptibility of erythrocytes to in vitro peroxidation during experimental Trypanosome congolense and $\mathrm{T}$ brucei infections in sheep. Israel J Vet Med. 58 (4)

Teka I. A.; Kazibwe A. J. N.; EL-Sabbagh N.; AL-Salabi M. I.; Ward C. P.; Eze A. A., Munday J. C.; Maser P.; Mtovu E.; Barrette M. P. and de Koning H. P. (2009): The DiamidineDiminazeneAceturate is a substrate for the highaffinity pentamidine transporter: Implications for the development of high resistance levels in Trypanosomes. Molpharmacol. 80(1): 110- 116.

Tonin A. A., Da Silva A. S., Costa M. M., Otto M. A., Thomé G. R., Tavares K. S., Miletti L. C., Leal M. R., Lopes S. T., Mazzanti C. M., Monteiro S. G., de La Rue ML. (2011). Diminazeneaceturate associated with sodium selenite and vitamin $\mathrm{E}$ in the treatment of Trypanosoma evansi infection in rats. ExpParasitol. 128(3):243-9.

Tuntasuvan, D., W. Jarabrum; N. Viseshakul; K. Mohkaew; S. Borisutsuwan; A. Theeraphan and N. Kongkanjana. (2003): Chemotherapy of surra in horses and mules with diminazeneaceturate. Vet Parasitology, 110: 227-233.

Umar I. A., Ogenyi E., OKodaso D., Kimeng E., Stancheva G. I., Omage J. J., Isah S. and Ibrahim M. A. (2007): Amelioration of anaemia and organ damage by combined intraperitoneal administration of vitamins $\mathrm{A}$ and $\mathrm{C}$ to Trypanosoma bruceibrucei - infected rats. Afr J Biotechnol. 6: 2083-6.

Villa, L. L. and Juliani, M. H. (1980): Induction of cytoplasmic petite mutations in yeast by quanidine hydrochloride. Combined treatment with other inducing agents.Mutat. Res., 71: 67-75.

WHO, World Health Organization. (2006): African Trypanosomosis (sleeping sickness). Fact sheet 259. Geneva: WHO.

Womack, S. Tarpley, H. L. Little, S. E., Latimer, K. S. (2001): Trypanosoma evansi in Horses, University of Georgia pp 12W.

Zhang, Z. Q., C. Giroud and T. Baltz (1991): In vivo and in vitro sensitivity of Trypanosoma evansi and T. equiperdumto diminazene, suramin, MelCy, quinapyramine and isometamidium. Acta Trop., 50(2):101-110. berenil. II. Characteristics of the process. Molec. Gene. Genet., 121, 295- 306.

Salomao, K; de Souza, E. M.; Carvalho, S. A.; de Silva, E. F.; Fraga, C. A. M.; Barbosa, H. S. and de Castro, S. L. (2010): In vitro and in vivo activity of 1,3,4- Thiadiazole-2- 
Scanning electron microscopy in the blood of mice Group I (control) uninfected and non-treated

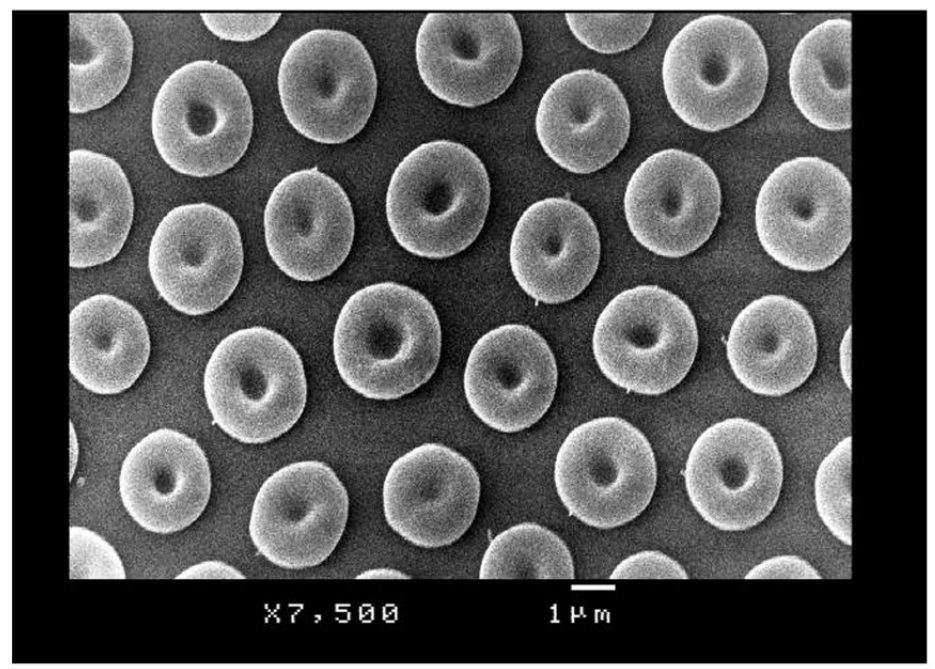

Fig. (A): SEM surface view in red blood cells which normally appear. These are round, biconcave disc.

Scanning electron microscopy in the blood of mice Group II (control) infected and non-treated
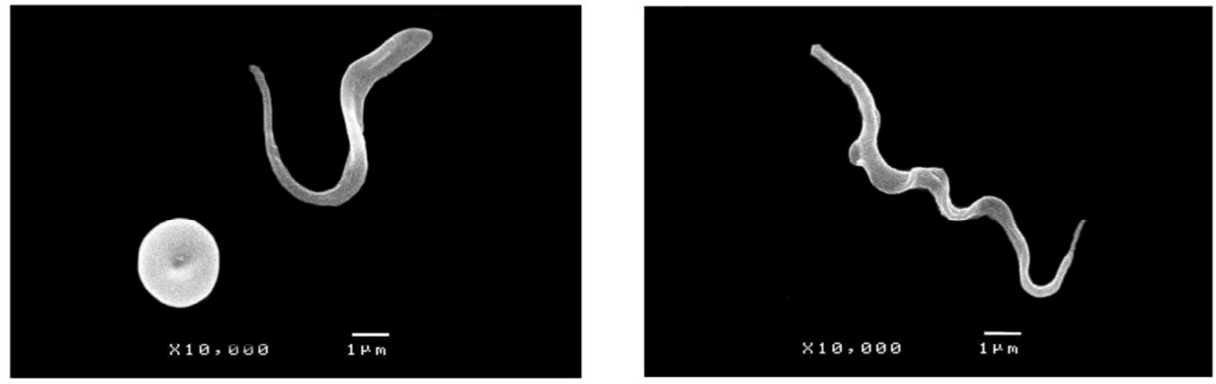

Fig. (1 and 2): SEM surface view of $T$. evansi in blood of mice, showed, body is relatively long and cylindrical has a tapering anterior end and pointed posterior end. Length of free flagellum and undulating membrane.

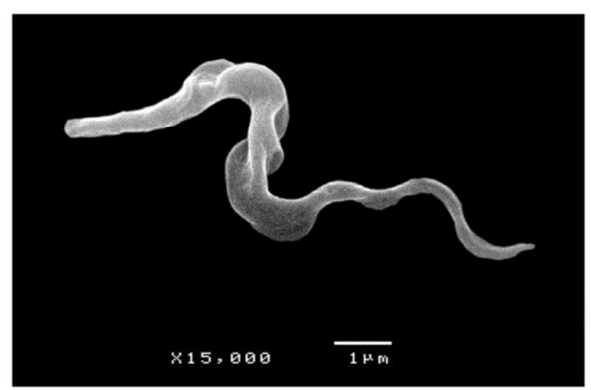

Fig. (3): SEM surface view of T. evansi showed, the body is relatively long, the flagellum arises and extends forming undulating membrane which is thrown into folds.

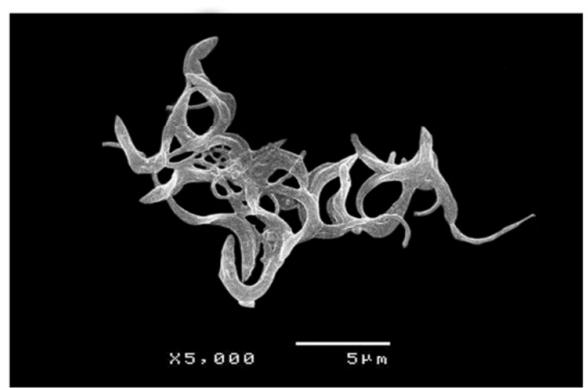

Fig. (4): SEM view of groups $T$. evansi in a normal shape with free flagellum and undulating membrane. 
Scanning electron microscopy in the blood of mice Group II (control) infected and non-treated

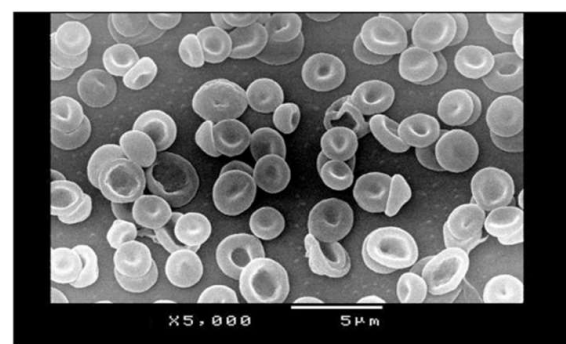

Fig. 5

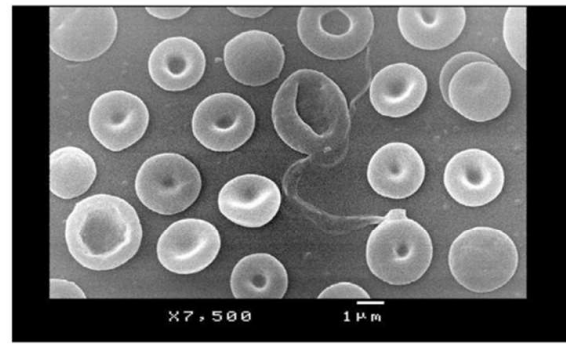

Fig. 7

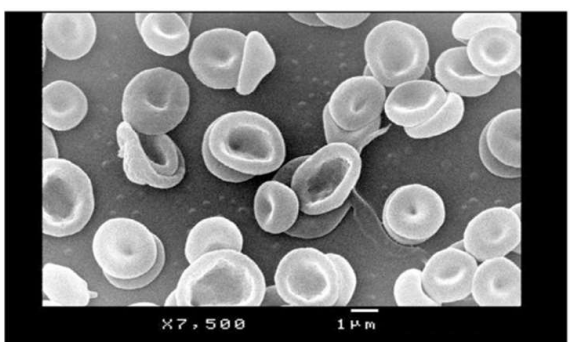

Fig. 6

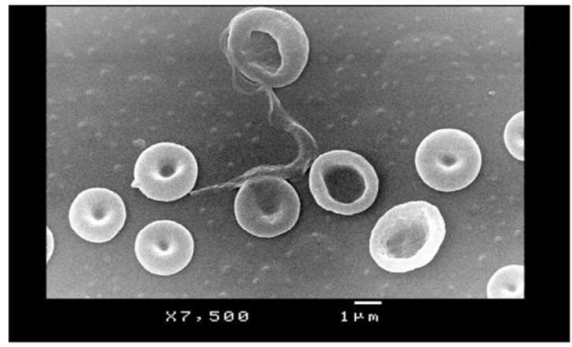

Fig. 8

Fig. (5, 6, 7 \& 8): SEM in the blood of inoculated mouse with $T$. evansi showed fusion of red blood cell and parasitophorus vacuolar membrane, disintegration rupture by cell and cell swelling should yeiled red blood cell ghosts.

\section{Scanning electron microscopy in the blood of mice Group II (control) infected and non-treated}

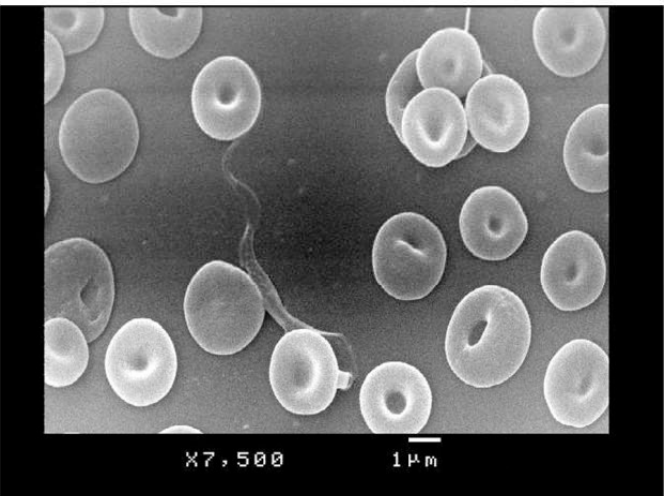

Fig. 9

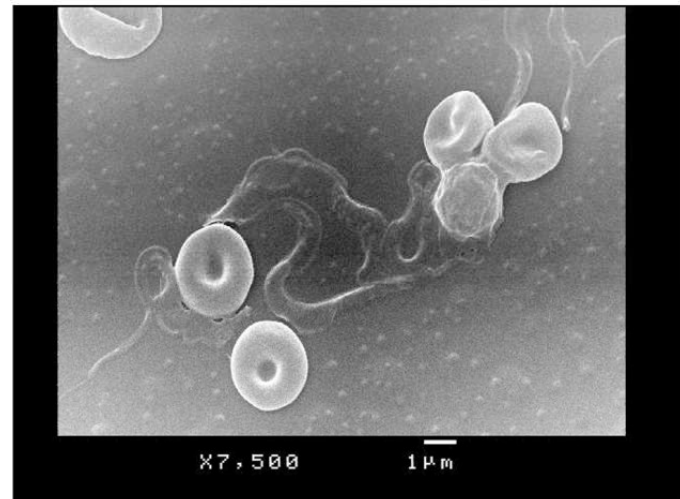

Fig. 10

Fig. (9 \& 10): SEM surface view showed RBC were constantly observed to adhere frimally to T. evansi. The RBC are keratocytosis and dought nut. 